\title{
Marker-assisted introgression of broad-spectrum blast resistance genes into the cultivated MR219 rice variety
}

\begin{abstract}
BACKGROUND: The rice cultivar MR219 is famous for its better yield and long and fine grain quality; however, it is susceptible to blast disease. The main objective of this study was to introgress blast resistance genes into MR219 through marker-assisted selection (MAS). The rice cultivar MR219 was used as the recurrent parent, and Pongsu Seribu 1 was used as the donor.

RESULTS: Marker-assisted foreground selection was performed using RM6836 and RM8225 to identify plants possessing blast resistance genes. Seventy microsatellite markers were used to estimate recurrent parent genome (RPG) recovery. Our analysis led to the development of 13 improved blast resistant lines with Piz, Pi2 and Pi9 broad-spectrum blast resistance genes and an MR219 genetic background. The RPG recovery of the selected improved lines was up to $97.70 \%$ with an average value of $95.98 \%$. Selected improved lines showed a resistance response against the most virulent blast pathogen pathotype, P7.2. The selected improved lines did not express any negative effect on agronomic traits in comparison with MR219.
\end{abstract}

CONCLUSION: The research findings of this study will be a conducive approach for the application of different molecular techniques that may result in accelerating the development of new disease-resistant rice varieties, which in turn will match rising demand and food security worldwide.

Keyword: Blast resistance; Gene introgression; Marker-assisted selection; MR219 rice variety 